\title{
Birth weight, biological maturation and obesity in adolescents: a mediation analysis
}

\author{
A. O. Werneck ${ }^{1 *}$, D. R. P. Silva ${ }^{1}$, P. J. Collings ${ }^{2}$, R. A. Fernandes ${ }^{3}$, E. R. V. Ronque ${ }^{1}$, M. J. Coelho-e-Silva ${ }^{4}$, \\ L. B. Sardinha ${ }^{5}$ and E. S. Cyrino ${ }^{1}$ \\ ${ }^{1}$ Study and Research Group in Metabolism, Nutrition, and Exercise - GEPEMENE, State University of Londrina - UEL, Londrina, Brazil \\ ${ }^{2}$ Bradford Institute for Health Research, Bradford NHS Foundation Trust, Bradford, UK \\ ${ }^{3}$ Scientific Research Group Related to Physical Activity (GICRAF), Laboratory of Investigation in Exercise (LIVE). Department of Physical Education. São Paulo State \\ University (UNESP), Presidente Prudente, Brazil \\ ${ }^{4}$ CIDAF (uid/dtp/04213/2016). University of Coimbra, Coimbra, Portugal \\ ${ }^{5}$ Exercise and Health Laboratory, CIPER, Faculdade de Motricidade Humana, Universidade de Lisboa, Cruz-Quebrada, Portugal
}

This study was aimed to investigate associations between birth weight and multiple adiposity indicators in youth, and to examine potential mediating effects by biological maturation. This was a school-based study involving 981 Brazilian adolescents aged between 10 and 17 years. Birth weight was reported retrospectively by mothers. Maturation was estimated by age of peak height velocity. Adiposity indicators included body mass index (BMI), waist circumference and percent body fat estimated from triceps and subscapular skinfolds. Multilevel mediation analyses were performed using the Sobel test, adjusted for chronological age, gestational age, cardiorespiratory fitness and socio-economic status. Except for body fat in girls, biological maturation partly or fully mediated $(P<0.05)$ positive relationships between birth weight with all other obesity indicators in both sexes with their respective values of indirect effects with $95 \%$ confidence intervals: BMI [boys: 0.44 (0.06-0.82); girls: 0.38 (0.13-0.64)], waist circumference [boys: 1.14 (0.22-2.05); girls: 0.87 (0.26-1.48)] and body fat [boys: 0.60 (0.13-1.07)]. To conclude, birth weight is associated with elevated obesity risk in adolescence and biological maturation seems to at least partly mediate this relationship.

Received 3 December 2016; Revised 16 March 2017; Accepted 20 March 2017; First published online 18 April 2017

Key words: adiposity, puberty, somatic maturation, motar activity

\section{Introduction}

In recent decades, the prevalence of childhood obesity has increased dramatically. ${ }^{1}$ Obesity negatively influences social life, ${ }^{2}$ can damage child metabolic health and exhibits moderate tracking from early life to adulthood ${ }^{3}$ when most health-related consequences manifest. It is recognized that the etiology of obesity is complex and involves epigenetic, environmental, behavioral and intrauterine factors, as well as a multitude of possible interacting effects. ${ }^{4}$ However, in spite of evidence that birth weight affects adult obesity ${ }^{5}$ and cardiovascular risk, ${ }^{6}$ the early postnatal period has received little research attention.

Other early life factors such as the timing of biological maturation further seem to contribute to greater adiposity development, ${ }^{7}$ but perhaps differentially in boys and girls, due to different timing and tempo of maturation. ${ }^{8}$ Other difference is the indicator, which in girls, there is a clear indicator that is menarche, different from boys where it is more difficult to determine timing and tempo of biological maturation. ${ }^{8}$ Previous studies have investigated birth weight and maturation relative to later obesity risk, but have failed to adjust for

\footnotetext{
*Address for correspondence: A. O. Werneck, Physical Education Department, Londrina State University, Rodovia Celso Garcia Cid, km 380, Campus Universitário, Londrina, Paraná 86051-990, Brazil.

(Email andreowerneck@gmail.com)
}

potentially key confounding variables and have not explored mediating factors. For instance, Wang et al. ${ }^{9}$ observed that girls with higher birth weight tended to be younger at menarche compared to girls with lower birth weight, but the association between birth weight and adiposity was not a topic of the study.

The aim of this study was to investigate the relation between birth weight and adolescent obesity, with specific focus on exploring possible mediating effects by maturational timing. We hypothesized that biological maturation would either partially or entirely mediate a positive association between birth weight and higher adolescent obesity (Fig. 1).

\section{Methods}

\section{Sample}

This was a cross-sectional study with retrospective data collection for birth weight in Brazilian adolescents aged between 10 and 17 years. All participants were enrolled in public schools in Londrina city which has an intermediate human development index. $^{10}$

Participant recruitment was performed in two stages. First, all public schools of the city were separated into regions (north, south, east, west and downtown) and two schools were randomly selected from each location. Subsequently, two to 


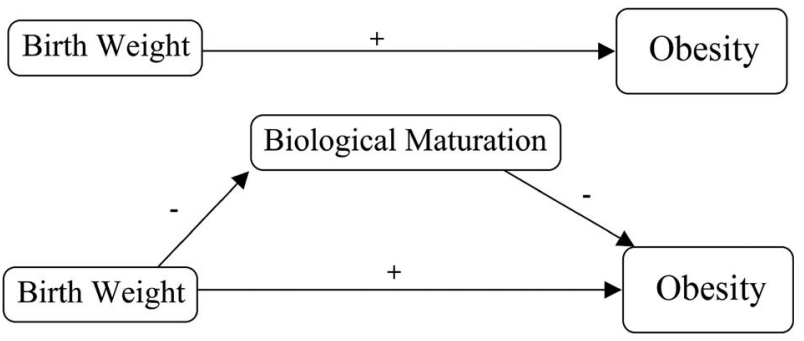

Fig. 1. Theoretical illustration of earlier biological maturation mediating an association between birth weight and obesity indicators in adolescence.

three classes were randomly identified in each school and all students within classes (except those using prescription medicine or undergoing treatment for an illness) were invited to participate in the study. Students that did not return a consent form signed by parents were ineligible. The total number of adolescents recruited was 1395 , but 414 failed to provide all data required for this analysis and were excluded. Reassuringly, we have previously reported that participants who provided complete data were representative of all adolescents that were initially enrolled to this study. ${ }^{11}$ The local ethics committee approved all of the study procedures which adhered to the principles of the Declaration of Helsinki.

\section{Birth weight}

Birth weight was obtained from maternal recall in response to the question 'What was the weight of your child at birth?' The answer was free text and values were converted to kilograms.

\section{Biological maturation}

Biological maturation was assessed using peak height velocity (PHV) which provides an indication of somatic maturity on the basis of measured height, sitting height and leg length. ${ }^{12}$ Chronological age was subtracted from the distance to PHV to estimate the age at occurrence of maturation, which was used as a continuous variable in analyses.

\section{Adiposity indicators}

Body mass index (BMI, $\mathrm{kg} / \mathrm{m}^{2}$ ) was calculated from body weight and height, which were measured according to the procedures described by Gordon et al. ${ }^{13}$ Central fat was derived from waist circumference, which was also measured according to recommendations ${ }^{14}$ with an anthropometric tape of $0.1 \mathrm{~cm}$ precision. Using standard procedures, ${ }^{15}$ triceps and subscapular skinfold thicknesses were measured by an experienced technician with a calibrated Lange ${ }^{\circledR}$ caliper (accuracy $=0.5 \mathrm{~mm}$ ). For quality control, the technical error of measurement (TEM) of skinfolds was calculated from repeated measurements taken from 90 adolescents who participated in a separate pilot project, but who were similar to the current study sample with respect to age, somatic maturity and body fat (data not shown). The TEMs were 3.5 and $4.8 \%$ for triceps and subscapular skinfolds, respectively. From the skinfold data, percent body fat was estimated. ${ }^{16}$

\section{Covariates}

Habitual physical activity was estimated by a 16 -item questionnaire that was self-completed by adolescents. ${ }^{17}$ The questionnaire asked about physical activity performed at school, in formal sports and leisure time; the sum of all domains constituted our habitual physical activity indicator. Additional details about the questionnaire, including reproducibility statistics and a description of a positive association between habitual physical activity and cardiorespiratory fitness in this sample (demonstrating face validity of the instrument), have been previously reported. ${ }^{18}$ Socio-economic status was assessed using the Brazilian Association of Marketing Research Companies questionnaire, ${ }^{19}$ which was answered by parents. Families were assigned to one of five hierarchical groups based on asset possession (such as ownership of a television, radio, washing machine or car) and the educational status of the head of the family. Gestational age was acquired by maternal recall in response to the question 'For how many weeks were you pregnant with your child?'. Finally, in the current study population we have previously shown that cardiorespiratory fitness is inversely associated with clustered metabolic risk (including waist circumference). ${ }^{11}$ In order to control analyses for cardiorespiratory fitness, a $20-\mathrm{m}$ shuttle run test was performed and peak oxygen consumption was estimated (in $\mathrm{ml} / \mathrm{kg} / \mathrm{min}$ ) using commonly implemented methods. ${ }^{20}$

\section{Statistical analysis}

Descriptive statistics are presented using frequencies, means and standard deviations. To investigate differences in variables between boys and girls $t$-tests and $\chi^{2}$ test were used. Partial correlations (adjusted for chronological age) were calculated between birth weight, maturation and adiposity variables.

Tests of mediation were conducted according to the principles of Baron and Kenny. ${ }^{21}$ In the first equation, the mediator variable (somatic maturation) was regressed onto the independent variable (birth weight). In a second set of equations, dependent variables (BMI, waist circumference and percent body fat) were regressed onto birth weight. Finally, in a third set of equations, dependent variables (obesity indicators) were regressed onto independent variables (birth weight) whilst controlling for the candidate mediator (biological maturation). To account for clustering of children within schools multilevel models were constructed ${ }^{22}$ and all equations were controlled for chronological age, gestational age, socio-economic status and cardiorespiratory fitness.

Mediating effects were identified if the following criteria were met: in the first equation, birth weight significantly predicted biological maturation; in the second equation, birth weight significantly predicted adiposity; in the third equation, biological maturation significantly predicted adiposity, and the association between birth weight and adiposity (from Equation 2) 
Table 1. Characteristics of the sample

\begin{tabular}{lllr}
\hline & Boys (402) & Girls (579) & \multicolumn{1}{c}{$P$} \\
\hline Chronological age (years) & $13.0 \pm 1.5$ & $12.8 \pm 1.4$ & 0.019 \\
Age of peak height velocity (years) & $14.4 \pm 0.7$ & $12.4 \pm 0.7$ & $<0.001$ \\
Birth weight (kg) & $3.26 \pm 0.72$ & $3.20 \pm 0.60$ & 0.183 \\
Body mass index $\left(\mathrm{kg} / \mathrm{m}^{2}\right)$ & $19.7 \pm 3.9$ & $19.9 \pm 4.1$ & 0.259 \\
Waist circumference $(\mathrm{cm})$ & $67.7 \pm 9.0$ & $65.5 \pm 8.0$ & $<0.001$ \\
Body fat (\%) & $18.5 \pm 7.3$ & $25.0 \pm 6.2$ & $<0.001$ \\
Physical activity (score) & $8.48 \pm 1.45$ & $7.66 \pm 1.25$ & $<0.001$ \\
Low socio-economic status (\%) & $31 \%$ & $36 \%$ & 0.353 \\
Gestational age (weeks) & $37.8 \pm 3.2$ & $37.8 \pm 3.6$ & 0.871 \\
Cardiorespiratory fitness & $41.9 \pm 4.5$ & $38.4 \pm 3.9$ & $<0.001$ \\
$\quad(\mathrm{ml} / \mathrm{kg} / \mathrm{min})$ & & & \\
\end{tabular}

Higher scores of physical activity indicates greater physical activity participation.

was either partially or entirely removed due to adjusting for somatic maturation. Analyses included the bootstrap method of resampling to estimate confidence intervals for total, direct and indirect effects. All statistics were carried out according to written procedures, ${ }^{22,23}$ in SPSS 22.0 and the level of significance was decided a priori as $P<0.05$.

\section{Results}

Table 1 presents the characteristics of the included 981 adolescents $(59 \%$ girls), who had a mean age of $12.9 \pm 1.4$ years; boys were slightly older than girls. The estimated age at attainment of PHV was expectedly lower in girls than boys, as were the levels of physical activity and cardiorespiratory fitness. Boys exhibited higher waist circumference than girls but a lower total percent body fat.

Partial correlations between birth weight, somatic maturation and adiposity variables are presented in Table 2. Birth weight was significantly negatively correlated with predicted age of PHV and positively correlated with all adiposity variables. Stronger negative correlations were seen between age of PHV and adiposity, indicating that later maturating adolescents were typically leaner.

The results of all components of mediation models are presented in Fig. 2. In boys, there was consistent evidence for partial mediation by maturation status $(P<0.05)$ and evidence of full mediation for waist circumference. In girls, all significant associations between birth weight and obesity indicators were entirely attenuated by somatic maturation; note there was no direct effect observed between birth weight and percent body fat and thus no scope for mediation. The proportion of mediation and the magnitude of indirect effects ( $95 \%$ confidence intervals) accountable to somatic maturation in the relation between birth weight and adiposity were identified as being, for boys and girls, respectively: $\mathrm{BMI}=39 \%, 0.44(0.06-0.82)$ and $66 \%, 0.38(0.13-0.64)$; waist circumference $=52 \%$, $1.14(0.22-2.05)$ and $66 \%, 0.87(0.26-1.48)$; body fat $=35 \%$,
Table 2. Partial correlations between birth weight, maturation and adiposity, stratified by sex

\begin{tabular}{|c|c|c|c|c|}
\hline & \multicolumn{2}{|c|}{ Birth weight } & \multicolumn{2}{|c|}{ Age of PHV } \\
\hline & Boys & Girls & Boys & Girls \\
\hline Birth weight & - & - & - & - \\
\hline Age of PHV & $-0.11^{*}$ & $-0.15^{*}$ & - & - \\
\hline Body mass index & $0.15^{*}$ & $0.10^{*}$ & $-0.57^{*}$ & $-0.43^{*}$ \\
\hline Waist circumference & $0.13^{*}$ & $0.10^{*}$ & $-0.62^{*}$ & $-0.49^{*}$ \\
\hline Body fat & $0.14^{*}$ & $0.09^{*}$ & $-0.45^{*}$ & $-0.39^{*}$ \\
\hline
\end{tabular}

All values are adjusted for chronological age.

PHV, peak height velocity.

${ }^{*} P<0.05$.

$0.60(0.13-1.07)$ and not significant for girls. Random effects of multilevel analysis are shown in Table 3. In general, with exception for body fat among girls, the standard deviation (estimation) of cluster level was at least $70 \%$ lower than the standard deviation of individual level.

\section{Discussion}

Adolescence represents a critical phase during which substantial changes in body composition occur. However, the correlates and determinants of these changes are not well established. We aimed to analyze the mediating role of biological maturation in the relationship between birth weight and obesity markers in adolescents. We observed that birth weight was inversely related to age of PHV and positively associated with adiposity in adolescents. In addition, estimated age of PHV was consistently mediated a positive relationship between birth weight and various adiposity indices in both sexes. The results of the current study highlight that birth weight and maturation seem to act as determinants of adolescent obesity, and that the sequence of events for birth weight may involve partial mediation by maturation.

It has previously been speculated that there are three key periods for the development of adiposity, the prenatal period, the timing of adiposity rebound and the transition to puberty. ${ }^{7}$ Birth weight reflects prenatal growth and development, ${ }^{24}$ and previous studies have described U-shaped associations between birth weight and adiposity development. ${ }^{25,26}$ This is somewhat consistent with observed positive relationships between birth weight and adiposity in adolescence. As maturation can be influenced by factors which include obesity status, ${ }^{8,27,28}$ it was hypothesized that birth weight could trigger a pathway responsible for obesity later in life that was mediated by earlier maturational timing. Indeed, like other studies which have indicated that early maturing adolescents tend to have higher prevalence of cardiovascular risk factors, ${ }^{29,30}$ it was found that earlier maturers exhibited higher adiposity levels. In line with the hypothesis of this study, somatic maturation either partially or fully mediated the relationships between birth weight and different indicators of obesity. 
Boys

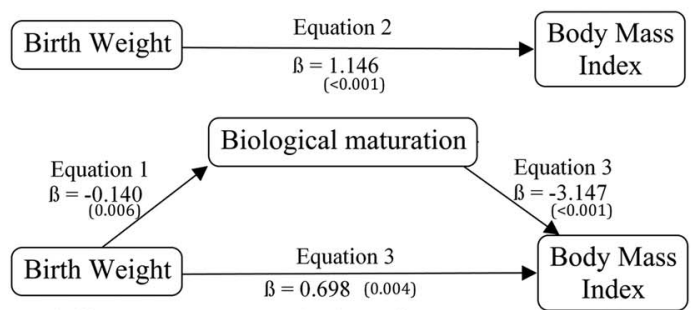

Total effect: 1.14 (0.38 to 1.89$)^{*}$. Direct effect: $0.70(0.11 \text { to } 1.28)^{*}$ Indirect effect: 0.44 (0.06 to 0.82$)^{*}$
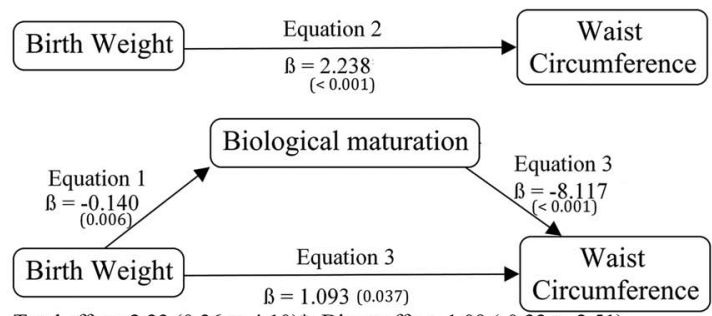

Total effect: $2.23(0.36 \text { to } 4.10)^{*}$. Direct effect: 1.09 ( -0.33 to 2.51$)$ Indirect effect: $1.14(0.22 \text { to } 2.05)^{*}$
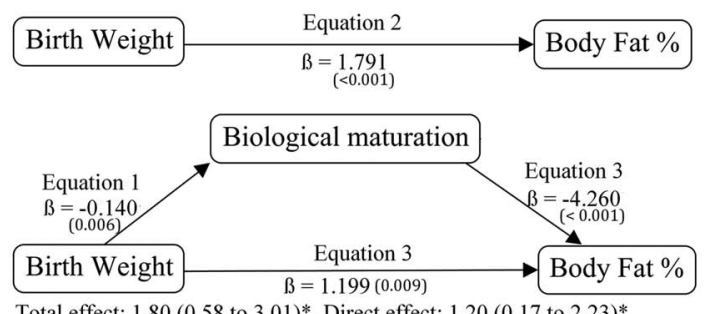

Total effect: 1.80 (0.58 to 3.01$)^{*}$. Direct effect: 1.20 (0.17 to 2.23$)^{*}$ Indirect effect: 0.60 (0.13 to 1.07$)^{*}$

\section{Girls}

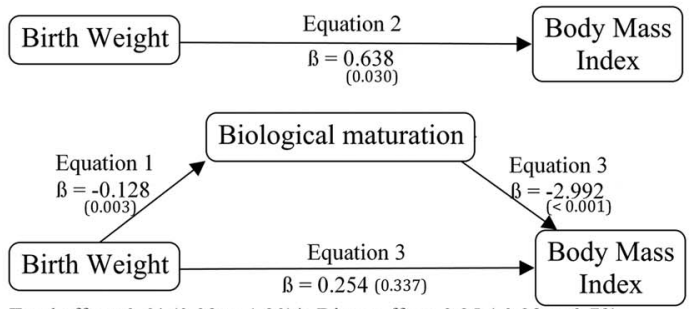

Total effect: 0.64 (0.08 to 1.20$)^{*}$. Direct effect: 0.25 ( -0.28 to 0.79$)$ Indirect effect: $0.38(0.13 \text { to } 0.64)^{*}$

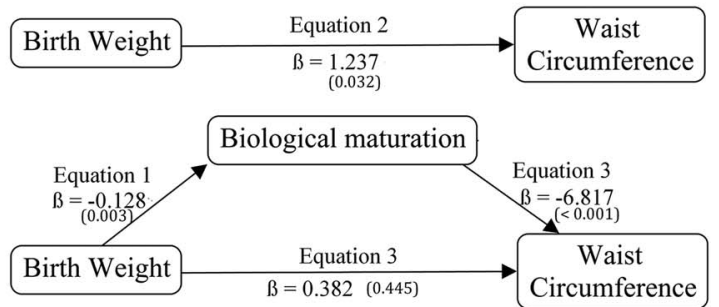

Total effect: $1.26(0.15 \text { to } 2.36)^{*}$. Direct effect: 0.38 (-0.50 to 1.26$)$ Indirect effect: 0.87 (0.26 to 1.48$)^{*}$

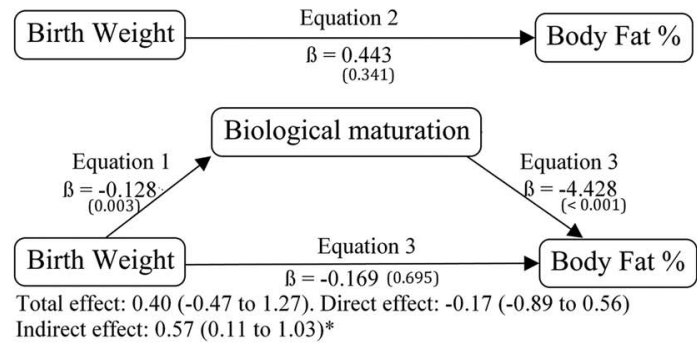

Fig. 2. Multilevel mediation models of biological maturation in relationship between birth weight and indicators of obesity in adolescents. Adjusted by chronological age, gestational age, cardiorespiratory fitness and socio-economic status. Data are presented with $\beta$ values as well as their corresponding $P$-value within parentheses. Total, direct and indirect effects are presented with $\beta$ and $95 \%$ confidence intervals derived from bootstrapping resampling method. ${ }^{*} p<0.05$.

Possible biological mechanisms available to support our proposed sequence of events [higher birth weight $>$ higher adiposity $>$ earlier maturation (lower APHV) $>$ higher adiposity] include a higher liberation of leptin by adipose tissue. Leptin plays an important role in puberty onset by influencing the gonadotropin-releasing hormone, ${ }^{8}$ possibly by activating kisspeptins (especially Kiss-1) and the GPR54 receptor which acts on the hypothalamus. ${ }^{27,28}$ Another possible mechanism linking adiposity with earlier biological maturation involves insulin resistance caused by high body fat; resultant hyperinsulinemia could decrease globulin binding of sex hormones and increase the level of sex steroid hormones in the blood. ${ }^{8,31}$ Furthermore, the roles of leptin and insulin may be interconnected, as insulin resistance can cause higher leptin sensitivity. $^{32,33}$ Subsequent earlier maturational timing from these events may increase obesity risk via a multitude of different parameters, including behavioral factors. For instance, obesity status has been shown to discourage sports participation and reduce physical activity levels. ${ }^{34}$ A role for activity behaviors at the earliest stage of our proposed chain of events seems less likely as, although there is evidence to the contrary ${ }^{35}$ meta-analyses suggest that birth weight is not an important determinant of physical activity in youth. ${ }^{36}$ Nonetheless, early gains in childhood adiposity that are driven by birth weight could be accentuated by inactivity and predispose to earlier maturation. For instance, Collings et al. ${ }^{37}$ have reported inverse cross-sectional associations between physical activity and adiposity in young childhood.

Another detail of this study was related with evidence of full mediating effects by APHV in girls and only partial mediation in boys. A possible explanation could be due to earlier maturational age in girls, meaning that birth and maturation were closer in proximity for girls compared with boys. ${ }^{8}$ In both sexes, we observed that biological maturation had a stronger association with adiposity than birth weight. Again, this difference may simply be down to proximity, as the event of maturation was closer in time to the measurement of adiposity. It may also be the case that biological maturational exerts a more direct (predominantly hormonally mediated) relationship with adiposity, while the relationship between birth weight and outcomes is more distal and indirect, and seemingly involves mediators such as biological maturation. 
Table 3. Random effects of multilevel equations from mediation models

\begin{tabular}{|c|c|c|c|c|}
\hline & \multicolumn{2}{|c|}{ Constant } & \multicolumn{2}{|c|}{ Residual } \\
\hline & Estimate & $95 \% \mathrm{CI}$ & Estimate & $95 \% \mathrm{CI}$ \\
\hline \multicolumn{5}{|l|}{ Body mass index } \\
\hline \multicolumn{5}{|l|}{ Boys } \\
\hline Equation 1 & 0.083 & $0.022-0.318$ & 0.617 & $0.561-0.668$ \\
\hline Equation 2 & 0.178 & $0.001-0.496$ & 3.484 & $3.223-3.766$ \\
\hline Equation 3 & 4.210 & $2.021-8.770$ & 2.895 & $2.680-3.127$ \\
\hline \multicolumn{5}{|l|}{ Girls } \\
\hline Equation 1 & 0.093 & $0.039-0.216$ & 0.522 & $0.488-0.558$ \\
\hline Equation 2 & 6.010 & $2.901-12.469$ & 3.523 & $3.295-3.767$ \\
\hline Equation 3 & 0.516 & $0.173-1.540$ & 3.137 & $2.931-3.357$ \\
\hline \multicolumn{5}{|c|}{ Waist circumference } \\
\hline \multicolumn{5}{|l|}{ Boys } \\
\hline Equation 1 & 0.083 & $0.022-0.318$ & 0.617 & $0.571-0.668$ \\
\hline Equation 2 & 1.039 & $0.269-4.015$ & 7.967 & $7.371-8.610$ \\
\hline Equation 3 & 0.653 & $0.099-4.309$ & 6.217 & $5.749-6.722$ \\
\hline \multicolumn{5}{|l|}{ Girls } \\
\hline Equation 1 & 0.093 & $0.040-0.216$ & 0.522 & $0.490-0.558$ \\
\hline Equation 2 & 0.169 & $2.241-1.271$ & 6.927 & $6.470-7.416$ \\
\hline Equation 3 & 0.947 & $0.359-2.496$ & 5.906 & $5.518-6.322$ \\
\hline \multicolumn{5}{|l|}{ Percent body fat } \\
\hline \multicolumn{5}{|l|}{ Boys } \\
\hline Equation 1 & 0.083 & $0.022-0.318$ & 0.617 & $0.571-0.668$ \\
\hline Equation 2 & 1.170 & $0.483-2.832$ & 6.051 & $5.599-6.540$ \\
\hline Equation 3 & 0.866 & $0.295-2.542$ & 5.458 & $5.048-5.901$ \\
\hline \multicolumn{5}{|l|}{ Girls } \\
\hline Equation 1 & 1.190 & $0.501-2.830$ & 5.566 & $5.200-5.958$ \\
\hline Equation 2 & 0.925 & $0.040-0.216$ & 0.522 & $0.488-0.558$ \\
\hline Equation 3 & 1.282 & $0.626-2.625$ & 5.059 & $4.726-5.416$ \\
\hline
\end{tabular}

CI, confidence intervals.

Strengths of the current study include a relatively large and homogenous cohort but with a wide range of birth weights from a developing country. Although confounding by factors such as excess maternal gestational weight gain cannot be ruled out, homogeneity of the sample will have reduced the potential for confounding by other factors and we further adjusted the analyses for cardiorespiratory fitness, ${ }^{38}$ socio-economic status and gestational age. Controlling for gestational age permitted differentiation between participants with low birth weight because of premature birth as opposed to growth restriction. We also tried to adjust for physical activity, ${ }^{39}$ however, this introduced problems of collinearity with cardiorespiratory fitness, hence physical activity was removed from the analysis. We incorporated valid indicators of adiposity ${ }^{5,6}$ and somatic maturation, ${ }^{12}$ but investigation of other indicators of development such as skeletal or sexual maturation would be insightful in future studies, as they can progress at different rates. ${ }^{40}$ Although birth weight and gestational age were measured retrospectively, maternal recalls are highly correlated with measured birth weight, ${ }^{41,42}$ and the presented data are highly comparable with the measured birth weights reported by a Brazilian birth cohort. ${ }^{35}$ With regards to the statistical analysis, the assumption of linearity was violated in the relationship between APHV and percent body fat. Moreover, there was no interaction between independent variable and mediator in the models.
In summary, earlier biological maturation mediated the observed positive associations between birth weight and multiple adiposity indicators in adolescent boys and girls. Future researcher of early exposures should be conducted with long-term and repeated measurements of exposure, outcome, mediators and confounders to aide better understanding of causality and the inter-relationships between birth weight, biological maturation and obesity.

\section{Acknowledgments}

The authors thank Alessandra Okino, Jair Oliveira, Danielle Venturini and Décio Barbosa for research support; Crisieli Tomeleri, Mariana Carnelossi and Sandra Kawaguti for acquisition of data; Coordination for the Improvement of Higher Education Personnel (CAPES/Brazil) for scholarships (D.R.P.S.) and National Council of Scientific and Technological Development $(\mathrm{CNPq} /$ Brazil $)$ for funding the project (483867/2009-8) and for scholarship of scientific initiation (A.O.W.) and productive research (E.R.V.R., E.S.C. and R.A.F.).

\section{Financial Support}

This work was supported by Brazilian Council of Scientific and Technological Development.

\section{Conflicts of Interest}

None.

\section{Ethical Standards}

The authors assert that all procedures contributing to this work were approved by the Ethics committee of Londrina State University according to the Helsinki declaration (process: 29216/2010).

\section{References}

1. Hallal PC, Andersen LB, Bull FC, et al. Global physical activity levels: surveillance progress, pitfalls, and prospects. Lancet. 2012; 380, 247-257.

2. Lee YS. Consequences of childhood obesity. Ann Acad Med Singapore. 2009; 38, 75-77.

3. Herman KM, Craig CL, Gauvin L, et al. Tracking of obesity and physical activity from childhood to adulthood: the Physical Activity Longitudinal Study. Int J Pediatr Obes. 2009; 4, 281-288.

4. McAllister EJ, Dhurandhar NV, Keith SW, et al. Ten putative contributors to the obesity epidemic. Crit Rev Food Sci Nutr. 2009; 49, 868-913.

5. Skilton MR, Siitonen N, Würtz P, et al. High birth weight is associated with obesity and increased carotid wall thickness in young adults: the cardiovascular risk in young Finns study. Arterioscler Thromb Vasc Biol. 2014; 34, 1064-1068.

6. Johnsson IW, Haglund B, Ahlsson F, et al. A high birth weight is associated with increased risk of type 2 diabetes and obesity. Pediatr Obes. 2015; 10, 77-83. 
7. Dietz WH. Periods of risk in childhood for the development of adult obesity - what do we need to learn? J Nutr. 1997; 127, 1884S-1886S.

8. Ahmed ML, Ong KK, Dunger DB. Childhood obesity and the timing of puberty. Trends Endocrinol Metab. 2009; 20, 237-242.

9. Wang Y, Dinse GE, Rogan WJ. Birth weight, early weight gain and pubertal maturation: a longitudinal study. Pediatr Obes. 2012; 7, 101-109.

10. Statistics BIoGa. Gross domestic product of municipalities, 2013. Retrieved 20 January 2016 from http://www.ibge.gov.br/cidadesat/ xtras/perfil.php?codmun=411370\&search=parana.

11. Silva D, Werneck AO, Collings P, et al. Cardiorespiratory fitness is related to metabolic risk independent of physical activity in boys but not girls from Southern Brazil. Am J Hum Biol. 2016; 28, 534-538.

12. Mirwald RL, Baxter-Jones ADG, Bailey DA, et al. An assessment of maturity from anthropometric measurements. Med Sci Sports Exerc. 2002; 34, 689-694.

13. Gordon CC, Chumled WC, Roche AF. Stature, recumbent length and weight. In Anthropometric Standardization Reference Manual (eds. Lohman TG, Roche AF, Martorell R), 1988. Human Kinetics Books: Champaign, IL. p. 3-8.

14. Katzmarzyk PT, Srinivasan SR, Chen W, et al. Body mass index, waist circumference, and clustering of cardiovascular disease risk factors in a biracial sample of children and adolescents. Pediatrics. 2004; 114, e198-e205.

15. Harrison G, Buskirk E, Carter L, et al. Skinfold thicknesses and measurement technique. In Anthropometric Standardization Reference Manual (eds. Lohman T, Roche A, Martorell R), 1988. Human Kinetics Books: Champaign, IL. p. 55-80.

16. Boileau RA, Lohman TG, Slaughter MH. Exercise body composition in children and youth. Scand J Sport Sci. 1985; 7, 17-27.

17. Baecke JAH, Burema J, Frijters JER. A short questionnaire for the measurement of habitual physical-activity in epidemiological-studies. Am J Clin Nutr. 1982; 36, 936-942.

18. Silva DR, Fernandes RA, Ohara D, et al. Correlates of sports practice, occupational and leisure-time physical activity in Brazilian adolescents. Am J Hum Biol. 2016; 28, 112-117.

19. ABEP. Dados com base no Levantamento Socioeconômico, retrieved from www.abep.org/Servicos/Download.aspx?id $=08$. Accessed in 20 January 2016.

20. Leger LA, Mercier D, Gadoury C, et al. The multistage 20 metre shuttle run test for aerobic fitness. J Sports Sci. 1988; 6, 93-101.

21. Baron RM, Kenny DA. The moderator-mediator variable distinction in social psychological research: conceptual, strategic, and statistical considerations. J Pers Soc Psychol. 1986; 51, 1173-1182.

22. Krull JL, MacKinnon DP. Multilevel modeling of individual and group level mediated effects. Multivariate Behav Res. 2001; 36, 249-277.

23. Preacher KJ, Hayes AF. SPSS and SAS procedures for estimating indirect effects in simple mediation models. Behav Res Methods Instrum Comput. 2004; 36, 717-731.

24. Whitaker RC, Dietz WH. Role of the prenatal environment in the development of obesity. J Pediatr. 1998; 132, 768-776.
25. Yu ZB, Han SP, Zhu GZ, et al. Birth weight and subsequent risk of obesity: a systematic review and meta-analysis. Obes Rev. 2011; $12,525-542$.

26. Chiavaroli V, Derraik JG, Hofman PL, et al. Born large for gestational age: bigger is not always better. J Pediatr. 2016; 170, 307-311.

27. Seminara SB, Messager S, Chatzidaki EE, et al. The GPR54 gene as a regulator of puberty. $N$ Engl J Med. 2003; 349, 1614-1627.

28. Colledge WH. GPR54 and kisspeptins. Results Probl Cell Differ. 2008; 46, 117-143.

29. Werneck AO, Silva DR, Souza MF, et al. Correlates of blood pressure according to early, on time, and late maturation in adolescents. J Clin Hypertens (Greenwich). 2016; 18, 424-430.

30. Boyne MS, Thame M, Osmond C, et al. The effect of earlier puberty on cardiometabolic risk factors in Afro-Caribbean children. J Pediatr Endocrinol Metab. 2014; 27, 453-460.

31. Klein KO, Baron J, Colli MJ, et al. Estrogen-levels in childhood determined by an ultrasensitive recombinant cell bioassay. J Clin Invest. 1994; 94, 2475-2480.

32. Lustig RH, Sen S, Soberman JE, et al. Obesity, leptin resistance, and the effects of insulin reduction. Int J Obes. 2004; 28, 1344-1348.

33. Jasik CB, Lustig RH. Adolescent obesity and puberty: the "perfect storm”. Ann N Y Acad Sci. 2008; 1135, 265-279.

34. Pietiläinen $\mathrm{KH}$, Kaprio J, Borg P, et al. Physical inactivity and obesity: a vicious circle. Obesity (Silver Spring). 2008; 16, 409-414.

35. Hildebrand M, Kolle E, Hansen BH, et al. Association between birth weight and objectively measured sedentary time is mediated by central adiposity: data in 10,793 youth from the International Children's Accelerometry Database. Am J Clin Nutr. 2015; 101, 983-990.

36. Oglund GP, Hildebrand M, Ekelund U. Are birth weight, early growth, and motor development determinants of physical activity in children and youth? A systematic review and meta-analysis. Pediatr Exerc Sci. 2015; 27, 441-453.

37. Collings PJ, Brage S, Ridgway CL, et al. Physical activity intensity, sedentary time, and body composition in preschoolers. Am J Clin Nutr. 2013; 97, 1020-1028.

38. Moliner-Urdiales D, Ruiz JR, Vicente-Rodriguez G, et al. Associations of muscular and cardiorespiratory fitness with total and central body fat in adolescents: the HELENA Study. $\mathrm{Br} J$ Sports Med. 2011; 45, 101-108.

39. Carson V, Rinaldi RL, Torrance B, et al. Vigorous physical activity and longitudinal associations with cardiometabolic risk factors in youth. Int J Obes (Lond). 2014; 38, 16-21.

40. Malina RM, Bouchard C, Bar-Or O. Growth, Maturation, and Physical Activity, 2nd edn, 2004. Human Kinetics, 728pp.

41. Adegboye AR, Heitmann B. Accuracy and correlates of maternal recall of birthweight and gestational age. BJOG. 2008; 115, 886-893.

42. O'Sullivan JJ, Pearce MS, Parker L. Parental recall of birth weight: how accurate is it? Arch Dis Child. 2000; 82, 202-203.

43. Swinburn BA, Sacks G, Hall KD, et al. The global obesity pandemic: shaped by global drivers and local environments. Lancet. 2011; 378, 804-814.

44. Fleiss JL. Statistical Methods for Rates and Proportions, 2nd edn, 1981. John Wiley and Son: New York. 